\title{
Polymerization depths of conventional and bulk fill composites photoactivated by different methods
}

\author{
Willian Fernando Felipe ${ }^{1}$, Weverteon Soares de Oliveira ${ }^{2}$, \\ Milton Edson Miranda ${ }^{1}$, Karina Andréa Novaes Olivieri ${ }^{1}$, \\ Rafael Pino Vitti ${ }^{3}$, William Cunha Brandt ${ }^{2}$
}

\author{
${ }^{1}$ School of Dentistry, São Leopoldo Mandic, Campinas, SP, Brazil. \\ ${ }^{2}$ Department of Implantology, School of Dentistry, University of Santo Amaro, São Paulo, SP, Brazil. \\ ${ }^{3}$ School of Dentistry, Herminio Ometto University Center, Araras, SP, Brazil. \\ e-mail: wffelipe@yahoo.com.br, weverteon@hotmail.com,memiranda@memiranda.com.br, karina_olivieri@hotmail. \\ com,rafapvitti@gmail.com, williamcbrandt@yahoo.com.br
}

\begin{abstract}
The aim of this study was to evaluate the depth of cure of conventional (Filtek Z350 and Esthet-X HD) and bulk fill resins composites (Filtek bulk fill flow and SDR) using different photoactivation methods. Samples were made using five discshaped matrices ( $1 \mathrm{~mm}$ high and $8 \mathrm{~mm}$ central diameter) with interposed polyester strips. The samples were photoactivated using different methods [continuous high-irradiance light (LCA), continuous low-irradiance light (LCB), and soft-start (SS)], maintaining $24 \mathrm{~J} / \mathrm{cm}^{2}$ radiant exposure. After 24h, Knoop microhardness test was performed at 5 depths (surface, 1 mm, $2 \mathrm{~mm}, 3 \mathrm{~mm}$ and $4 \mathrm{~mm}$ ). The Knoop microhardness were analyzed by ANOVA two-way and Tukey’s test (5\%). Conventional resins presented the highest results up to $2 \mathrm{~mm}$ depth, except for Esthet-X photoactived by LCB, which showed significant lower Knoop hardness from $2 \mathrm{~mm}$ depth. Bulk fill resins photoactivated with LCA and SS had the highest results in $4 \mathrm{~mm}$ depth. The LCA and SS photoactivation methods produce suitable photoactivation in conventional composites up to $2 \mathrm{~mm}$ and bulk fill up to $4 \mathrm{~mm}$ depth and the bulk fill composites present higher polymerization depth than conventional composites.
\end{abstract}

Keywords: Dental curing lights; hardness test; photoactivation; polymerization; resin

\section{INTRODUCTION}

The optical properties and the adhesion capacity to the dental structures, provide wide utilization of composite resins in restorative dentistry [1]. Conventionally, the restoring technique involves the application of composite resin increments of up to $2 \mathrm{~mm}$ of thickness, in order to allow correct photoactivation of the increment and minimize the shrinkage and shrinkage stress resulting from the material polymerization process [2]. The incremental technique is relatively sensitive and demands a considerable chair time. These factors associated to clinical problems of the restorations, such as post-operative sensitivity, fissure formation on the tooth/restauration interface, marginal pigmentation, secondary caries, cusp deflection, fractures of the enamel edges, displacement of the restoration, and dental element fracture; encourage the development of new composite resins in an attempt to overcome these problems [3, 4].

Recently, a new category of restoring composites (bulk fill composite resins) was proposed to restore cavities ranging from 4 to $6 \mathrm{~mm}$ with a single increment, providing an easier restoration technique [less sensitive] with less chair time compared to the incremental technique [5-7]. Although the single increment technique $(\sim 5 \mathrm{~mm})$ increases the trajectory of the photoactivation light to reach the deepest layer of the resin, the manufacturers claim that these materials present higher polymerization depth, as well as lower shrinkage and shrinkage stress that the conventional composite resins. Bulk fill composite resins have modified resinous monomers and reduction in the size for the filler particle [5-8].

The bulk fill resins can be classified into low (flow), medium, and high viscosity. Besides low filler particles, a reasonable polymerization depth can be obtained using specific polymerization modulator, improving the translucency, or more effective photoinitiators. However, the smallest amount of particles may reduce the mechanic properties of bulk fill flow resins [5-8].

Manufacturers do not provide the amount of the radiant exposure required to polymerize the composite resins; how- 
ever, a radiant exposure between 12 and $24 \mathrm{~J} / \mathrm{cm}^{2}$ is enough to cure the composite resins restorations of up to $2 \mathrm{~mm}$ thickness $[9,10]$. The radiant exposure change according to commercial brand and composite resin color [9]. The suitable radiant exposure to cure composite resin can be obtained through different methods of photoactivation, such as high-irradiance continuous light (LCA), continuous low-irradiance light (LCB), and soft-start (SS) [11]. The delivered radiant exposure on the surface of the composite resins should be enough to provide a complete polymerization of the material. Therefore, it is important to select the correct irradiance of the light-emitting diode (LED) curing light, and the photoactivation time for each type of composite resin to obtain clinical success in the restorative treatment $[12,13]$.

The aim of this study was to evaluate the polymerization depth (surface, $1 \mathrm{~mm}, 2 \mathrm{~mm}, 3 \mathrm{~mm}, 4 \mathrm{~mm}$ ) of conventional and bulk fill composite resins using different photoactivation methods (LCA, LCB and SS). Two hypotheses were tested: (i) different microhardness results would be found in bulk fill resins thickness tested and (ii) photoactivation methods with lower irradiance would produce lower microhardness.

\section{MATERIAL AND METHODS}

All composite resins (A2 shade) used in the present study are described in the Table 1.

Table 1: Composite resins composition.

\begin{tabular}{|c|c|c|}
\hline \multirow[b]{2}{*}{$\begin{array}{l}\text { COMPOSITE RESIN, MANUFAC- } \\
\text { TURER (BATCH NUMBER) }\end{array}$} & \multicolumn{2}{|l|}{ COMPOSITION } \\
\hline & FILLER & RESIN \\
\hline $\begin{array}{l}\text { Filtek Z350 XT, } \\
\text { 3M ESPE (455134) }\end{array}$ & $\begin{array}{c}\text { Non-agglomerated/non-aggregated silica } \\
\text { ( } 20 \mathrm{~nm}) \text {, } \\
\text { non-agglomerated/non-aggregated zirconia } \\
\text { (4 to } 11 \mathrm{~nm}) \text {, and aggregated zirconia/silica } \\
\text { cluster (comprised of } 20 \mathrm{~nm} \text { silica and } 4 \text { to } 11 \mathrm{~nm} \text { zirco- } \\
\text { nia particles). }\end{array}$ & $\begin{array}{l}\text { bisGMA, UDMA, } \\
\text { TEGDMA, bisE- } \\
\text { MA(6). }\end{array}$ \\
\hline $\begin{array}{l}\text { Esthet-X HD, } \\
\text { Dentsply (530658) }\end{array}$ & $\begin{array}{l}\text { Barium fluoroborosilicate glass with a mean particle } \\
\text { size }(<1 \mu \mathrm{m}) \text { and nanofiller silica }(0.04 \mu \mathrm{m}) \text {. }\end{array}$ & $\begin{array}{l}\text { bisGMA, TEGD- } \\
\text { MA, } \\
\text { bisEMA. }\end{array}$ \\
\hline $\begin{array}{l}\text { Filtek Bulk Fill Flowable Restorative, } \\
\text { 3M ESPE (N620070) }\end{array}$ & $\begin{array}{c}\text { Combination of zirconia/silica }(0.01 \text { to } 3.5 \mu \mathrm{m}) \text { and } \\
\text { ytterbium trifluoride }(0.1 \text { to } 5.0 \mu \mathrm{m}) \text {. }\end{array}$ & $\begin{array}{l}\text { bisGMA, } \\
\text { UDMA, bisE- } \\
\text { MA(6), polyacryla- } \\
\text { te resins. }\end{array}$ \\
\hline $\begin{array}{l}\text { SureFil SDR Flow, } \\
\text { Dentsply (1503202) }\end{array}$ & $\begin{array}{l}\text { Barium-alumino-fluoro-borosilicate glass, strontium } \\
\text { alumino-fluoro-silicate glass, titanium dioxide and iron } \\
\text { oxide pigments. }\end{array}$ & $\begin{array}{l}\text { EBPADMA, } \\
\text { TEGDMA, modi- } \\
\text { fied-UDMA. }\end{array}$ \\
\hline
\end{tabular}

bis-GMA: bisphenol A-glycidyl methacrylate; UDMA: urethane dimethacrylate; TEGDMA: triethyleneglycol dimethacrylate; bis-EMA(6): ethoxylated bisphenol A glycol dimethacrylate; EBPADMA: ethoxylated Bisphenol A dimethacrylate.

\subsection{Microhardness and polymerization depth}

For the Knoop microhardness test, samples $(\mathrm{n}=10)$ were made using five disc-shaped matrices $(1 \mathrm{~mm}$ high and $8 \mathrm{~mm}$ central diameter) with interposed polyester strips. Each composite resin was inserted into the matrix in a single increment. A polyester strip and glass slide were used in order to extrude excess of the material. This procedure was repeated 4 times using 4 new matrices, totaling 5 matrices (5 $\mathrm{mm}$ depth).

LED BluePhase (Ivoclar Vivadent, Schaan, Liechtenstein) equipment was used, following the photoactivation protocols described in the Table 2. After the photoactivation, the samples were stored for $24 \mathrm{~h}$ at $37^{\circ} \mathrm{C}$ in a dry and light free environment. The radiant exposure was standardized at $24 \mathrm{~J} / \mathrm{cm}^{2}$ for all groups. 
Table 2: Description of the photoactivation protocols (irradiance and exposure time).

\begin{tabular}{c|c}
\hline PHOTOACTIVATION METHOD & PROTOCOL \\
\hline High-irradiance continuous light (LCA) & $1200 \mathrm{~mW} / \mathrm{cm}^{2}$ for $20 \mathrm{~s}$ \\
\hline Low-irradiance continuous light (LCB) & $150 \mathrm{~mW} / \mathrm{cm}^{2}$ for $160 \mathrm{~s}$ \\
\hline Soft-start (SS) & $150 \mathrm{~mW} / \mathrm{cm}^{2}$ for $10 \mathrm{~s}+1200 \mathrm{~mW} / \mathrm{cm}^{2}$ for $19 \mathrm{~s}$ \\
\hline
\end{tabular}

In the SS group, the different luminous irradiance was obtained using a pre-calibrated standard spacer. The spacer was made with acrylic resin (JET, Artigos Odontológicos Clássico, São Paulo, SP, Brazil). A hole at the center of the spacers was create to permit the light pass.

The Knoop microhardness was measured using a hardness tester HMV 2000 (Shimadzu, Tokyo, Japan) with $50 \mathrm{~g}$ load applied during 10s. Three indentations were made in the cross-sectional area at depths tested (from 0 to $4 \mathrm{~mm}$ - Figure 1) from the top surface.

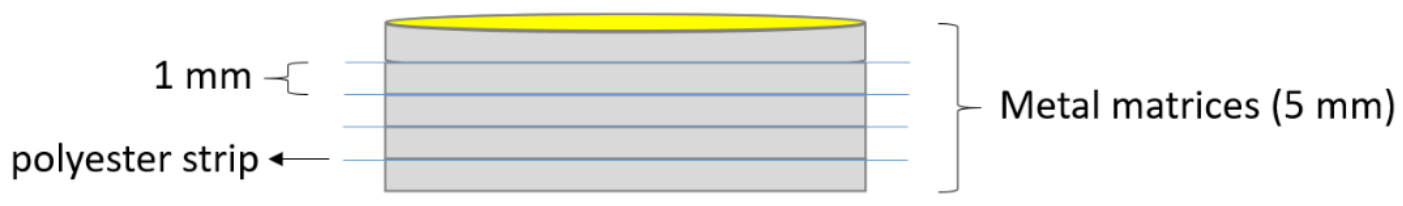

Figure 1: Metal matrices interposed with polyester strips and evaluated depths.

For each specimen depth, the average of the three indentations was obtained $\left(\mathrm{KHN}-\mathrm{Kgf} / \mathrm{mm}^{2}\right)$.

\subsection{Analysis of light transmittance}

The LED curing light source was analyzed (1) without composite resins $(0 \mathrm{~mm})$ and (2) with the composite resins thicknesses ( $1 \mathrm{~mm}, 2 \mathrm{~mm}, 3 \mathrm{~mm}$ and $4 \mathrm{~mm}$ ) using a digital power meter (Ophir Optronics, Danvers, MA, USA).

\subsection{Statistical analysis}

The Knoop microhardness data was subjected to statistical analysis using Kolmogorov-Smirnov and Analysis of Variance (ANOVA two-way; thickness and photoactivation method), with Tukey test with a pre-set alpha of 0.05 in SigmaStat program 3.5 (Systat Software Inc., San Jose, Califórnia, USA).

\section{RESULTS}

The ANOVA showed a statistically significant interaction between the factors $(\boldsymbol{\rho}<0,001)$ for all the composite resins.

Filtek Z350 XT resin obtained the highest Knoop microhardness values up to $2 \mathrm{~mm}$ depth, regardless of the photoactivation method used (Table 3). LCA showed higher Knoop microhardness values with statistically significant differences in $1 \mathrm{~mm}, 3 \mathrm{~mm}$, and $4 \mathrm{~mm}$ depths than LCB and SS. For $4 \mathrm{~mm}$ depth, the microhardness cannot be evaluated for LCB and SS photoactivation methods. 
Table 3: Knoop microhardness means $( \pm \mathrm{SD})$ for different composite resins, evaluated depths and photoactivation methods.

\begin{tabular}{|c|c|c|c|c|}
\hline \multirow[b]{2}{*}{ RESIN } & \multirow[b]{2}{*}{ DEPTH } & \multicolumn{3}{|c|}{ PHOTOACTIVATION METHODS } \\
\hline & & LCA & LCB & SS \\
\hline \multirow{5}{*}{ Filtek Z350 XT } & $0 \mathrm{~mm}$ & $54.1(19.0)$ A.a & $47.8(2.9) \mathrm{A}, \mathrm{a}$ & $46.1(0.8) \mathrm{A}, \mathrm{a}$ \\
\hline & $1 \mathrm{~mm}$ & $57.6(17.4) \mathrm{A}, \mathrm{a}$ & $45.1(2.0) \mathrm{A}, \mathrm{b}$ & $47.4(3.6) \mathrm{A}, \mathrm{b}$ \\
\hline & $2 \mathrm{~mm}$ & $48.5(12.9) \mathrm{AB}, \mathrm{a}$ & $42.0(0.7) \mathrm{A}, \mathrm{a}$ & $46.3(0.7) \mathrm{A}, \mathrm{a}$ \\
\hline & $3 \mathrm{~mm}$ & $38.8(12.6) \mathrm{B}, \mathrm{a}$ & $0.0(0.0) \mathrm{B}, \mathrm{c}$ & $26.9(1.4) \mathrm{B}, \mathrm{b}$ \\
\hline & $4 \mathrm{~mm}$ & $9.0(6.5) \mathrm{C}, \mathrm{a}$ & $0.0(0.0) \mathrm{B}, \mathrm{b}$ & $0.0(0.0) \mathrm{C}, \mathrm{b}$ \\
\hline \multirow{5}{*}{ Esthet-X HD } & $0 \mathrm{~mm}$ & $23.6(5.6) \mathrm{AB}, \mathrm{a}$ & $26.5(2.6) \mathrm{A}, \mathrm{a}$ & $24.2(2.1) \mathrm{A}, \mathrm{a}$ \\
\hline & $1 \mathrm{~mm}$ & $25.5(4.0) \mathrm{A}, \mathrm{a}$ & $26.1(2.5) \mathrm{A}, \mathrm{a}$ & $25.1(0.7) \mathrm{A}, \mathrm{a}$ \\
\hline & $2 \mathrm{~mm}$ & $20.9(1.8) \mathrm{B}, \mathrm{a}$ & $20.9(2.4) \mathrm{B}, \mathrm{a}$ & $24.0(3.4) \mathrm{A}, \mathrm{a}$ \\
\hline & $3 \mathrm{~mm}$ & $8.8(7.9) \mathrm{C}, \mathrm{b}$ & $0.0(0.0) \mathrm{C}, \mathrm{c}$ & $13.5(3.4) \mathrm{B}, \mathrm{a}$ \\
\hline & $4 \mathrm{~mm}$ & $1.1(3.3) \mathrm{D}, \mathrm{a}$ & $0.0(0.0) \mathrm{C}, \mathrm{a}$ & $0.0(0.0) \mathrm{C}, \mathrm{a}$ \\
\hline \multirow{5}{*}{ Filtek Bulk Fill Flow } & $0 \mathrm{~mm}$ & $22.6(2.3) \mathrm{A}, \mathrm{a}$ & $19.5(0.7) \mathrm{B}, \mathrm{b}$ & $24.5(1.4) \mathrm{A}, \mathrm{a}$ \\
\hline & $1 \mathrm{~mm}$ & $24.9(3.3) \mathrm{A}, \mathrm{a}$ & $19.9(0.8) \mathrm{B}, \mathrm{b}$ & $23.0(2.4) \mathrm{A}, \mathrm{a}$ \\
\hline & $2 \mathrm{~mm}$ & $23.9(2.8) \mathrm{A}, \mathrm{a}$ & $24.0(1.8) \mathrm{A}, \mathrm{a}$ & $24.9(2.4) \mathrm{A}, \mathrm{a}$ \\
\hline & $3 \mathrm{~mm}$ & $22.1(1.9) \mathrm{A}, \mathrm{a}$ & $19.2(3.6) \mathrm{B}, \mathrm{b}$ & $24.9(3.1) \mathrm{A}, \mathrm{a}$ \\
\hline & $4 \mathrm{~mm}$ & $21.9(4.5) \mathrm{A}, \mathrm{a}$ & $0.0(0.0) \mathrm{C}, \mathrm{b}$ & $25.9(3.8) \mathrm{A}, \mathrm{a}$ \\
\hline \multirow{5}{*}{ SureFil SDR Flow } & $0 \mathrm{~mm}$ & 22.9 (3.4) A,a & $15.7(0.8) \mathrm{A}, \mathrm{b}$ & $23.2(2.0) \mathrm{A}, \mathrm{a}$ \\
\hline & $1 \mathrm{~mm}$ & $24.0(2.8) \mathrm{A}, \mathrm{a}$ & $17.5(1.1) \mathrm{A}, \mathrm{b}$ & $25.3(2.1) \mathrm{A}, \mathrm{a}$ \\
\hline & $2 \mathrm{~mm}$ & $25.1(2.4) \mathrm{A}, \mathrm{a}$ & $16.5(1.0) \mathrm{A}, \mathrm{b}$ & $23.4(1.8) \mathrm{A}, \mathrm{a}$ \\
\hline & $3 \mathrm{~mm}$ & $24.8(2.5) \mathrm{A}, \mathrm{a}$ & $14.4(0.9) \mathrm{A}, \mathrm{b}$ & $25.1(1.4) \mathrm{A}, \mathrm{a}$ \\
\hline & $4 \mathrm{~mm}$ & $23.2(5.6) \mathrm{A}, \mathrm{a}$ & $0.0(0.0) \mathrm{B}, \mathrm{b}$ & $21.8(8.8) \mathrm{A}, \mathrm{a}$ \\
\hline
\end{tabular}

Means followed by distinct letters indicate significant difference $(\rho<0.05)$. Capital letter: comparison in column for each resin composite; lower-case letter: comparison in row. LCA - High-irradiance continuous light; LCB - Low-irradiance continuous light; SS - Soft-start.

The Esthet-X HD composite obtained the highest Knoop microhardness values up to $2 \mathrm{~mm}$ depth for all photoactivation methods. For $3 \mathrm{~mm}$ depth, SS showed the highest Knoop microhardness, but in $4 \mathrm{~mm}$ depth the microhardness cannot be evaluated. There was statistical significant decrease in microhardness from $2 \mathrm{~mm}$ depth for LCA and LCB groups, and from $3 \mathrm{~mm}$ depth for SS.

The Bulk Fill SureFill SDR Flow composite had the same Knoop microhardness results from 0 to $4 \mathrm{~mm}$ depth for the LCA and SS groups. For LCB, the $2 \mathrm{~mm}$ depth showed the highest Knoop microhardness mean and in $4 \mathrm{~mm}$ depth the microhardness cannot be evaluated.

The Filtek Bulk Fill composite obtained suitable Knoop hardness results in $4 \mathrm{~mm}$ depth for all groups, except for SS. Among the photoactivation methods, LCA and SS presented the highest Knoop hardness values in all depths. methods.

The Table 4 shows the irradiance values obtained in all depths of composite resins and evaluated photoactivation

Table 4: Irradiance $\left(\mathrm{mW} / \mathrm{cm}^{2}\right)$ according to resin composite, photoactivation methods and depth.

\begin{tabular}{c|c|c|c|c|c|c|c|c}
\hline \multirow{2}{*}{ DEPTH } & \multicolumn{2}{|c|}{ FILTEK Z350 XT } & \multicolumn{2}{|c|}{ ESTHET-X HD } & \multicolumn{2}{c|}{$\begin{array}{c}\text { FILTEK BULK } \\
\text { FILL FLOW }\end{array}$} & $\begin{array}{c}\text { BULK FILL SUREFILL } \\
\text { SDR FLOW }\end{array}$ \\
\cline { 2 - 9 } & LCA & LCB & LCA & LCB & LCA & LCB & LCA & LCB \\
\hline $0 \mathrm{~mm}$ & 1080 & 180 & 1080 & 180 & 1080 & 180 & 1080 & 180 \\
\hline $1 \mathrm{~mm}$ & 690 & 127 & 592 & 85 & 662 & 111 & 756 & 133 \\
\hline $2 \mathrm{~mm}$ & 352 & 113 & 310 & 70 & 380 & 90 & 366 & 105 \\
\hline $3 \mathrm{~mm}$ & 254 & 90 & 197 & 55 & 275 & 80 & 282 & 90 \\
\hline $4 \mathrm{~mm}$ & 183 & 50 & 183 & 30 & 197 & 65 & 225 & 70 \\
\hline
\end{tabular}




\section{DISCUSSION}

The microhardness analysis is the more frequent method used to evaluate the conversion degree of the composite resins [8]. This test is more sensitive than equipment based on vibrational spectroscopy, such as Fourier-transform infrared spectroscopy (FTIR), because it is able to detect small changes in the degree of conversion after the polymer formation (after the network is cross-linked) [14].

The first tested hypothesis in this study was accepted because different values of microhardness were found for different polymerization depths in the bulk fill composite/LCB group. For LCA and SS groups, the microhardness values did not present statistical difference for both bulk fill resins (Table 3). The Knoop hardness values for the bulk fill resins showed an effective polymerization depth, because the results do not present statistical difference between depths (from $0 \mathrm{~mm}$ to 4 $\mathrm{mm}$ ) in LCA and SS groups.

Increasing the thickness of conventional composite resins promotes a better curing light absorption and scattering, and less light penetration within the layers of the cured material. The higher degree of conversion and microhardness on top surface (low thickness - from 0 to $2 \mathrm{~mm}$ ) than bottom surface (high thickness -3 and $4 \mathrm{~mm}$ ) can be explained by the highest number of photons on top surface. The density might decrease gradually in each thickness with a similar gradual decrease in refractive index. Therefore, curing light radiant exposure is reduced with increasing thickness, jeopardizing the Knoop microhardness as well as the degree of conversion [15]. For composite resin restorations with $>2 \mathrm{~mm}$ thickness, the incremental layering technique is considered a gold standard for restorations with conventional composite resins [16].

The bulk fill composite resins can be polymerized using increments up to $4 \mathrm{~mm}$ to create a lower polymerization shrinkage stress. This can be explained by higher light transmission through translucent bulk fill thickness than conventional composite resins [17]. The translucency was measured in this study using light transmittance analysis [18], where the bulk fill composite resins present, in general, a light transmittance slightly superior to conventional composite resins (Table 4). Moreover, bulk fill composite resins exhibit higher light transmission properties due to reduction of light scattering at the filler-matrix interface [17].

On other hand, LCB results in low radiant exposure that reach the bottom surfaces of the composite resins. The composite resins must present $\geq 80 \%$ bottom/top percentage microhardness to achieve a suitable polymerization $[19,20]$. So the results of the present study demonstrate that the low irradiance photoactivation (LCB) is capable to cure the bulk fill resins up to $3 \mathrm{~mm}$ thickness (Table 3 ).

The second hypothesis was also accepted. For all composite resins in the LCB group, different depths showed different microhardness values. Higher microhardness values is result of a combination of photo and thermal effects. High light irradiances immobilize the system increasing quickly the viscosity, but also generate a temporary excess of free volume improving the mobility of the monomers. This mobility allows the system to reach higher degrees of conversion $[2,4,5,7,8,13]$. At high light irradiances, most of the reaction will occur in the unrelaxed state (post-gel), whereas at low light irradiances the resin is able to relax more during polymerization, reducing its internal mobility and its final conversion $[4,7,13,19]$. Moreover, the increase of the light irradiance also increases the maximum temperature reached during polymerization, and consequently the mobility of the polymer chains $[2,4,8,11]$. The increase of the irradiation time cannot compensate low values of light irradiance (higher times for LCB than LCA; Table 2). In general, the LCA and SS groups did not present difference in Knoop microhardness values. It is important to emphasize that modulated photoactivation can minimize the problems related to light-curing materials, i.e., to initiate the photoactivation of the composite resins with less light irradiance, followed by a final photoactivation with high irradiance $[21,22,23]$.

Ideally, the photoactivation equipments should offer a light beam collimated with minimum reduction of the irradiance in clinically relevant distances [up to $8 \mathrm{~mm}$ from the top] [24]. The manufacturers of conventional composite resins tend to maximize the filler content to obtain the best mechanical properties, and at the same time, minimize the filler size to improve the aesthetic. The bulk fill composite resins contain a smaller amount of fillers with high size. It seems that the decrease the amount as well as increase size of the fillers plays a crucial effect in higher translucency of bulk fill composite resins [25].

Furthermore, the monomer composition and filler content influence the viscosity and they are important parameters related to reaction kinetics and degree of conversion, because their also affects the polymerization mobility [5, 7, 8, 13, 17, $20,23]$. Both bulk fill composites resins tested in the present study are flow materials in comparison to conventional composites. They have modified monomers and different amount/size of filler particles (Table 1). The Bulk Fill SureFill SDR Flow have photoactive groups incorporated to the urethane methacrylate monomers (Table 1) that are capable to react with the camphorquinone. This reaction helps to module the polymerization and control the shrinkage stress (high mobility), besides to create a homogeneous polymer network $[4,7,23]$. The Filtek Bulk Fill Flow contains polyacrylate resins and bisEMA (Table 1). These materials have higher molecular weight and lower viscosity than bisGMA, that does not possess hydroxyl group in its structure and are present in higher amount in conventional composite resins (Table 1). Thus, bisEMA-based resins containing urethane monomers present higher values of hardness and degree of conversion in comparison to the conventional composite resins [5]. 
It is important to emphasize that the good performance of the bulk fill composite resins is directly related to the viscosity of these materials. In the present study, bulk fill flow resins present the best polymerization effectiveness, since high viscous composite resins contain a greater amount of inorganic fillers $[12,25,26]$. Differences in the refractive indices between the fillers and the organic matrix (filler/matrix ratio) of the composite resins affect their translucency [8, 12, 23, 25]. Different parameters must be evaluated in futures studies, because other physicochemical properties of the composites resins are important factors to predict clinical success of the restorations.

\section{CONCLUSIONS}

The photoactivation methods LCA and SS (higher irradiance) produce suitable photoactivation in conventional composites up to $2 \mathrm{~mm}$ and bulk fill up to $4 \mathrm{~mm}$ depth. The bulk fill composites present the same polymerization (microhardness) in all depths $(0-4 \mathrm{~mm})$.

\section{BIBLIOGRAPHY}

[1] Maas, M.S., Alania, Y., Natale, L.C., et al., "Trends in restorative composites research: what is in the future?”, Brazilian Oral Research, v. 31, supl. 1, pp. e55, Aug. 2017.

[2] Kim, R.J., Kim, Y.J., Choi, N.S., et al., "Polymerization shrinkage, modulus, and shrinkage stress related to tooth-restoration interfacial debonding in bulk-fill composites", Journal of Dentistry, v. 43, n. 4, pp. 430-439, Apr. 2015.

[3] BECK, F., LETTNER, S., GRAF, A., et al., "Survival of direct resin restorations in posterior teeth within a 19-year period (1996-2015): a meta-analysis of prospective studies”, Dental Materials, v. 31, n. 8, pp. 958-985, Aug. 2015.

[4] SOARES, C.J., FARIA-E-SILVA, A.L., RODRIGUES, M.P., et al., Polymerization shrinkage stress of composite resins and resin cements - what do we need to know?", Brazilian Oral Research, v. 31, supl. 1, pp. e62, Aug. 2017.

[5] FRONZA, B.M., RUEGGEBERG, F.A., BRAGA, R.R., et al., "Monomer conversion, microhardness, internal marginal adaptation, and shrinkage stress of bulk-fill resin composites”, Dental Materials, v. 31, n. 12, pp. 1542-1551, Dec. 2015.

[6] HAYASHI, J., ESPIGARES, J., TAKAGAKI, T., et al., "Real-time in-depth imaging of gap formation in bulk-fill resin composites", Dental Materials, v. 35, n. 4, pp. 585-596, Apr. 2019.

[7] CISNEROS, A.Z., ARMAS, A.S, “A comparative study of bulk-fill composites: degree of conversion, post-gel shrinkage and cytotoxicity”, Brazilian Oral Research, v. 32, pp. e17, Mar. 2018.

[8] REIS, A.F., ESTPHAL. M., AMARAL, R.C.D., et al., "Efficiency of polymerization of bulk-fill composite resins: a systematic review”, Brazilian Oral Research, v. 31, supl. 1, pp. e59, Aug. 2017.

[9] CALHEIROS, F.C., KAWANO, Y., STANSBURY, J.W., et al., "Influence of radiant exposure on contraction stress, degree of conversion and mechanical properties of resin composites", Dental Materials, v. 22, n. 9, pp. 799-803, Sep. 2006.

[10] FAN, P.L., SCHUMACHER, R.M., AZZOLIN, K., et al., "Curing-light irradiance and depth of cure of resin-based composites tested according to international standards", Journal of the American Dental Association, v. 133, n. 4, pp. 429-434, Apr. 2002.

[11] ROCHA, M.G., DE OLIVEIRA, D., CORREA, I.C., et al., "Light-emitting diode beam profile and spectral output influence on the degree of conversion of bulk fill composites", Operative Dentistry, v. 42, n. 4, pp. 418-427, Jul/Aug. 2017.

[12] FLURY, S., PEUTZFELDT, A., LUSSI, A, “Influence of increment thickness on microhardness and dentin bond strength of bulk fill resin composites”, Dental Materials, v. 30, n. 10, pp. 1104-1112, Oct. 2014.

[13] ALSHALI, R.Z., SALIM, N.A., Satterthwaite, "Post-irradiation hardness development, chemical softening, and termal stability of bulk-fill and conventional resin-composites", Journal of Dentistry, v. 43, n. 2, pp. 209-2018, Feb. 2015.

[14] RUEGGEBERG, F.A., CRAIG, R.G, "Correlation of parameters used to estimate monomer conversion in a lightcured composite”, Journal of Dental Research, v. 67, n. 6, pp. 932-937, Jun. 1988.

[15] CEBALLOS, L., FUENTES, M.V., TAFALLA, H., et al., "Curing effectiveness of resin composites at different exposure times using LED and halogen units", Medicina Oral Patologia Oral y Cirugia Bucal, v. 14, n. 1, pp. E55-56, Jan. 2009. 
[16] VAN ENDE, A., DE MUNCK, J., VAN LANDUYT, K.L., et al., "Bulk-filling of high C-factor posterior cavities: effect on adhesion to cavity-bottom dentin”, Dental Materials, v. 29, n. 3, pp. 269-277, Mar. 2013.

[17] CZASCH, P., ILIE, N., "In vitro comparison of mechanical properties and degree of cure of bulk fill composites", Clinical Oral Investigations, v. 17, n. 1, pp. 227-235, Jan. 2013.

[18] LI, X., PONGPRUEKSA, P., VAN MEERBEEK, B., et al., "Curing profile of bulk-fill resin-based composites", Journal of Dentistry, v. 43, n. 6, pp. 664-672, Jun. 2015.

[19] ALRAHLAHA, A., SILIKAS, N., WATTS, D.C., "Post-cure depth of cure of bulk fill dental resin-composites", Dental Materials, v. 30, n. 2, pp. 149-154, Feb. 2014.

[20] BENETTI, A.R., HAVNDRUP-PEDERSEN, C., HONORÉ, D., et al., "Bulk-fill resin composites: polymerization contraction, depth of cure, and gap formation”, Operative Dentistry, v. 40, n. 2, pp. 190-200, Mar. 2015.

[21] MEHL, A., HICKEL, R., KUNZELMANN, K.H, "Physical properties and gap formation of light-cured composites with an without "softstart polymerization", Journal of Dentistry, v. 31, supl. 1, pp. e55, Aug. 2017.

[22] ROY, K.K., KUMAR, K.P., JOHN, G., “A comparative evaluation of effect of modern-curing lights and curing modes on conventional and novel-resin monomers", Journal of Conservative Dentistry, v. 21, n. 1, pp. 68-73, Jan-Feb. 2018.

[23] MÜNCHOW, E.A., MEEREIS, C.T.W., DE OLIVEIRA DA ROSA, W.L., "Polymerization shrinkage stress of resin-based dental materials: a systematic review and meta-analyses of technique protocol and photo-activation strategies", Journal of the Mechanical Behavior of Biomedical Materials, v. 82, pp. 77-86, Jun. 2018.

[24] PRICE, R.B., SHORTALL, A.C., PALIN, W.M., "Contemporary issues in light curing”, Operative Dentistry, v. 39, n. 1, pp. 4-14, Jan-Feb. 2014.

[25] BUCUTA, S., ILIE, N., "Light transmittance and micro-mechanical properties of bulk fill vs. conventional resin based composites", Clinical Oral Investigations, v. 18, n. 8, pp. 1991-2000, Nov. 2014.

[26] GARCIA, D., YAMAN, P., DENNISON, J., et al., "Polymerization shrinkage and depth of cure of bulk fill flowable composite resins", Operative Dentistry, v. 39, n. 4, pp. 441-448, Jul-Aug. 2014.

\section{ORCID}

Weverteon Oliveira

William Felipe

Milton Miranda

William Brandt

Karina Olivieri

Rafael Vitti http://orcid.org/0000-0001-8324-9693

http://orcid.org/0000-0001-6723-1872

http://orcid.org/0000-0002-5410-6500

http://orcid.org/0000-0002-6362-0499

http://orcid.org/0000-0001-8843-8901

http://orcid.org/0000-0001-6366-5868 